\title{
A SURVEY OF THE BACTERIAL DIVERSITY IN THE CUP FILLER OF DENTAL CHAIR UNITS
}

\author{
Vítor Silva $^{1}$, Vânia Figueira' ${ }^{1}$, Helena Figueiral², Célia M. Manaia ${ }^{*}$ \\ ${ }^{1}$ CBQF/Escola Superior de Biotecnologia, Universidade Católica Portuguesa, 4200-072 Porto, Portugal; ${ }^{2}$ Faculdade de Medicina \\ Dentária da Universidade do Porto, Porto, Portugal
}

Submitted: January 03, 2010; Returned to authors for corrections: January 18, 2010; Approved: March 14, 2011.

\begin{abstract}
Water from the cup filler of dental chair units (CFDC) was observed to contain sphingomonads, environmental mycobacteria and methylobacteria, among other minor bacteria. Some of the bacteria detected are recognized opportunistic pathogens. Some of these, tended to persist over time.
\end{abstract}

Keywords: Dental unit water; water safety; bacterial diversity

Dental chair units supply irrigation water to different instruments, namely for surgery practices and to the patient rinse cup $(11 ; 15 ; 16)$. For this reason, the water supplied by dental chair units must be microbiologically safe $(11 ; 18 ; 24)$. Previous studies evidenced that the microorganisms of dental unit water lines have origin either in the water supplying system or, in a less extent, result from the oral cavity $(19 ; 23)$. In spite of the low density these organisms may have in the water supplying, the plastic narrow bore tubing, and the water stagnation facilitate their adherence, originating biofilm aggregates able to spread through the whole network of water tubing in the dental chair units $(6 ; 11 ; 18 ; 24)$. Biofilm aggregates in the dental unit water lines may cause considerable variations on the abundance and diversity of bacteria, mainly due to detachment phenomena (6).

In this study we were interested in assessing some aspects poorly addressed in the literature available in the microbiology of dental water lines. Namely, we were interested in determining if in the same geographic region it is expected to have similar patterns of bacterial diversity and in assessing the dynamics of bacteria between different dental chairs and sampling periods. With these objectives, we surveyed the diversity of bacteria found in the water supplied by the cup filler of dental chair units in two University Dental School Clinics (Clinic A and Clinic B), examined in two distinct sampling moments. Clinics A and B are situated in the Northern region of Portugal and, although dist only about 20 $\mathrm{km}$, are served by different potable water suppliers. A total of 64 chairs (KaVo SYSTEMATICA 1059; Biberach an der Riss, Germany) is available in clinic A and 32 (PERFORMER Adec; Newberg, USA) in clinic B, in use for more than ten years. Samples were collected between January and April 2008 from the cup filler of dental chairs (CFDC) and from taps served by the same water supplying system, located in the same room. In total, 20 samples were collected in each dental clinic, corresponding to $11 \mathrm{CFDC}$, six of which were sampled twice (with the second sample collected one month after the first, a period to which corresponded in average 600-700 cup refilling episodes), and three tap water samples. Water was allowed to run for about one minute before collection, samples were analyzed within a maximum period of $2 \mathrm{~h}$. Bacteria were isolated on Pseudomonas Isolation Agar (PIA, Difco, Sparks,

*Corresponding Author. Mailing address: Escola Superior de Biotecnologia, Universidade Católica Portuguesa, 4200-072 Porto, Portugal.; Tel: +351 22 5580059 Fax: +351 22 5090351.; E-mail: cmmanaia@esb.ucp.pt 
Maryland, USA), R2A (Difco Sparks, Maryland, USA) and Tergitol-7 Agar (TTC , Oxoid, Basingstoke, Hampshire, England). Volumes of 5 or $10 \mathrm{~mL}$ were filtered, in duplicate, through membranes with $0.45 \mu \mathrm{m}$ pore size (Albet Barcelona, Spain), placed onto the culture-media and incubated at $30^{\circ} \mathrm{C}$. Cultures were observed for the diversity of colony forming units (CFU), after three and seven days of incubation. Bacterial isolates were recovered according to the following criterion one to three colonies of morphotypes represented by one to four colonies, three colonies when a morphotype had five representatives in the same plate, five colonies when a morphotype was represented by ten or more colonies. Cultures were purified on Plate Count Agar (Pronadisa, Madrid, Spain) and maintained at $-80^{\circ} \mathrm{C}$ in nutrient broth supplemented with $15 \%(\mathrm{v} / \mathrm{v})$ glycerol. In order to assess the diversity of bacteria, its recurrence in the same CFDC in different sampling dates or its distribution by distinct CFDC, the isolates were genotyped using the M13 primer (5'GAGGGTGGCGGTTCT3'). Except for mycobacteria, DNA was extracted from crude cell lysates. Mycobacterial DNA was extracted using Genomic DNA Purification Kit (FERMENTAS, Vilnius, Lithuania), according to the manufacturer instructions, after freezing-thawing and lisozime treatment. Random amplified polymorphic DNA (RAPD) was performed in a total volume $12.5 \mu$ with: $0.75 \mathrm{U}$ Taq polymerase, $1.5 \mathrm{mM}$ of $\mathrm{MgCl}_{2}$ (Fermentas, Vilnius, Lithuania), $0.2 \mathrm{mM}$ of each $\mathrm{dNTP}, 1.0 \mu \mathrm{M}$ of M13 primer and $0.25 \mu \mathrm{L}$ of DNA. PCR reactions were performed in a thermocycler Tprofessional Basic Gradient of Biometra with the following program: 5 minutes at $94{ }^{\circ} \mathrm{C}$, followed of 45 cycles of amplification of 1 minute at $94{ }^{\circ} \mathrm{C}, 1$ minute at $34{ }^{\circ} \mathrm{C}$ and 2 minutes at $72{ }^{\circ} \mathrm{C}$, and a final extension step of 10 minutes at $72{ }^{\circ} \mathrm{C}(5)$. Polymorphic DNA fragments were analyzed by electrophoresis in a $1.5 \%$ agarose gel in Tris-acetate-EDTA buffer. Patterns differing in more than two bands were considered distinct genotypes. Bacteria identification was carried on as described on basis of the analysis of 16S rRNA gene sequence using universal primers $27 \mathrm{~F}$ and $1492 \mathrm{R}$ (5).
PCR was performed in a reaction mixture of $50 \mathrm{~mL}$ containing 1x PCR buffer (75mM Tris- $\mathrm{HCl}, \mathrm{pH} 8.8$ at $251{ }^{\circ} \mathrm{C}, 20 \mathrm{mM}$ $\left(\mathrm{NH}_{4}\right) 2 \mathrm{SO}_{4}, 0.01 \%$ Tween 20), $2.5 \mathrm{mM} \mathrm{MgCl}, 200 \mathrm{mM}$ of each dNTP, $2.5 \mathrm{U}$ of Taq polymerase (Fermentas, Vilnius, Lithuania), $1 \mathrm{mM}$ of each primer and $2 \mathrm{~mL}$ of crude cell lysate, under the following conditions: $5 \mathrm{~min}$ at $95^{\circ} \mathrm{C}$, followed by 30 cycles of amplification of $1 \mathrm{~min}$ at $94{ }^{\circ} \mathrm{C}, 1 \mathrm{~min}$ at $55^{\circ} \mathrm{C}$ and $1.5 \mathrm{~min}$ at $72^{\circ} \mathrm{C}$, and a final extension step of $10 \mathrm{~min}$ at $72^{\circ} \mathrm{C}$. Yeast isolates were identified with the commercial kit ID $32 \mathrm{C}$ (bioMérieux, Capronne, France), according to the manufacturer instructions.

The current study surveyed only the diversity of culturable bacteria. Although we admit that the use of cultureindependent approaches could give a magnified perspective of such bacterial diversity, we observed that in surface water culture-dependent and culture-independent approaches (using the culture-independent methods DGGE and 454 pyrosequecing) revealed the presence of the same predominant bacterial groups (26). Moreover, the use of culture-dependent methods has the advantage of allowing future studies of virulence or antibiotic resistance determinants or molecular epidemiology. The culture medium R2A, with a reduced selective character, allowed the recovery of the highest counts and diversity of bacteria. In contrast, on the culture medium TTC, selective for enterobacteriaceae, was observed the lowest bacterial diversity. Although, in general in clinic A bacterial counts were higher than in the clinic B, it was possible to detect considerable variations either between different CFDC sampled in the same day or in the same CFDC sampled in different dates. Risk assessment studies aiming the establishment of control measures to assure the safe use of the dental water units have indicated the value of 200 colonyforming units per $\mathrm{ml}$ of aerobic bacteria as the maximum admissible in the water lines (17). We observed that bacterial counts were within the range of the recommended value, although in some cases it was 10-1000 times lower. The lower values observed may be due to the fact that we examined the 
water of the cup filler, and not directly from the water line (narrow bore tubing).

The patterns of bacterial genera isolated in both clinics were remarkably different (Table 1). Two bacterial groups were observed to prevail in clinic A - yellow pigmented bacteria of the family Sphingomonadaceae and environmental mycobacteria. Other organisms, such as Gram-positive cocci, methylotrophs, endospore formers or other Proteobacteria had an occasional presence, although observed in some episodes of recurrence, as was the case of Cupriavidus gilardii. Yeasts identified as Cryptococcus albidus were also isolated occasionally in clinic A, from a single CFDC. Most of the isolates recovered from clinic B CFDC belonged to the genus Methylobacterium, followed by Gram-positive bacteria. The isolation of Proteobacteria in this clinic, namely of the genera Acinetobacter or Roseomonas, was occasional.

Table 1. Diversity, distribution and recurrence of the different bacterial groups in the CFDC in clinics A and B.

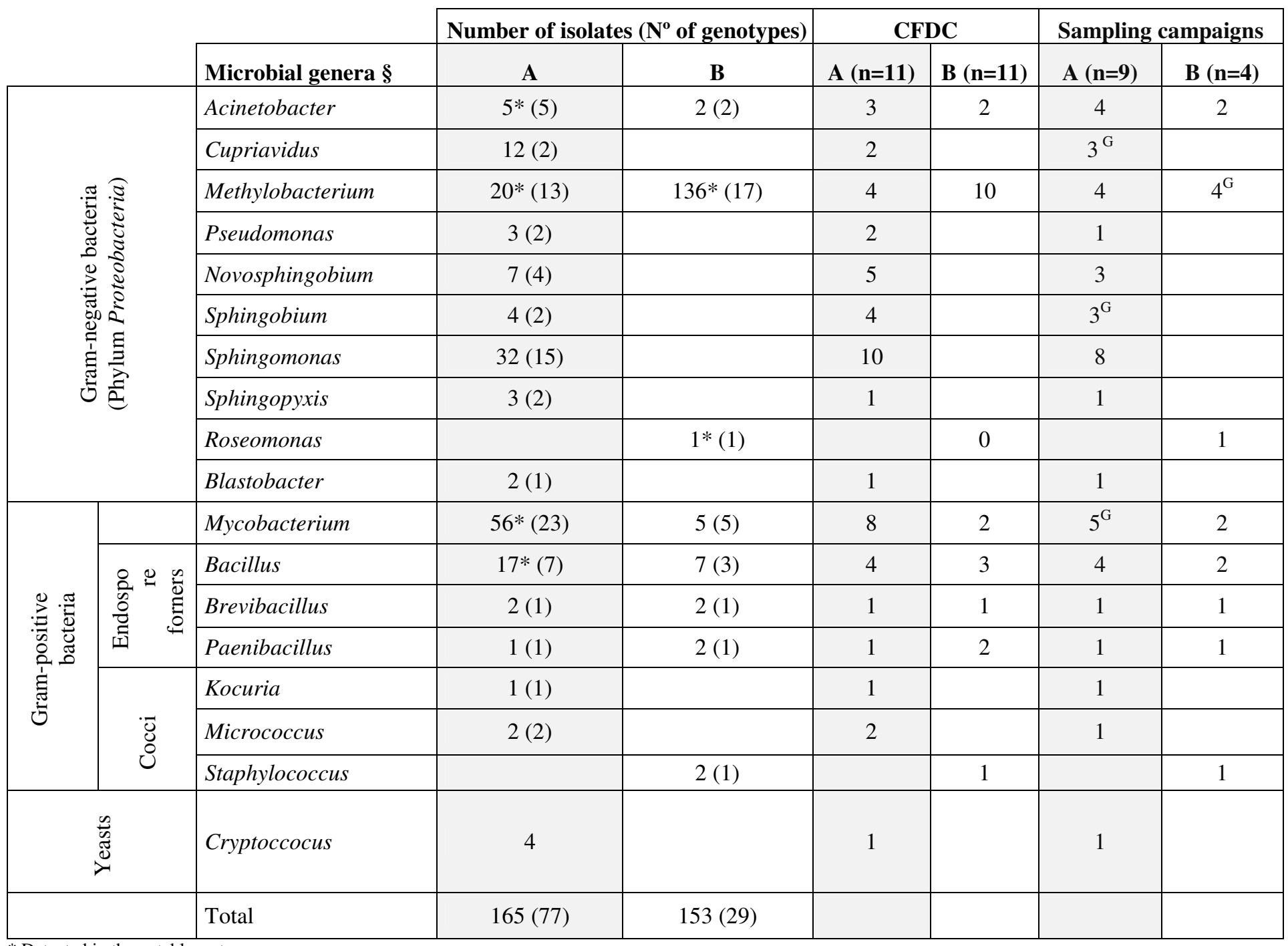

* Detected in the potable water

G The same genotype was detected in two consecutive samplings of the same CFDC.

$\S$, Whenever possible, identification to the species level indicated: Acinetobacter junii; Bacillus licheniformis; Bacillus pumilus; Bacillus simplex; Cupriavidus gilardii; Cupriavidus metallidurans; Methylobacterium aquaticum; Methylobacterium fujisawaense; Methylobacterium oryzae; Methylobacterium populi; Mycobacterium bolletii; Mycobacterium chelonae; Mycobacterium fortuitum; Mycobacterium lazari; Mycobacterium massiliense; Mycobacterium mucogenicum; Novosphingobium stygium; Paenibacillus taichungensis; Pseudomonas stutzeri; Sphingobium yanoikuyae; Sphingomonas paucimobilis; Staphylococcus epidermidis; Staphylococcus saprophyticus. 
Genotyping was used as a tool to get a more detailed picture of the bacterial diversity. Seventy-seven genotypes were observed in clinic A and 29 in clinic B, both in the CFDC and controls (tap water) (Table 1). Controls exhibited a lower diversity than that observed in CFDC, with 16 distinct genotypes in clinic A (6 found simultaneously in CFDC) and 5 in clinic B (3 found simultaneously in CFDC). Despite this difference, in general, isolates from controls and CFDC belonged to the same taxonomic groups. In contrast, most of the genotypes observed in the CFDC, were not detected in the controls (61 in clinic A and 24 in clinic B).

About $20 \%$ of the genotypes detected in each clinic were distributed by different CFDC (17/77 in clinic A and 6/29 in clinic B). The most widespread were, mainly, but not exclusively, members of the predominant taxa sphingomonads (comprising the genera Sphingomonas, Sphingobium, Novosphingobium, Sphyngopyxis), Cupriavidus spp., Mycobacterium spp., Methylobacterium spp. and Bacillus spp. in clinic A and as Methylobacterium spp. and Bacillus spp. in clinic B). The presence of the same genotype in different CFDC suggests a common origin for those bacteria, rather than a colonization of each dental chair. Such a common origin is, most probably, the water supplying system $(3 ; 11 ; 14 ; 21)$.

In half of the CFDC that were sampled twice, it was possible to detect the same genotype in two consecutive analyses. This was observed for members of the genera Cupriavidus and Mycobacterium and the family Sphingomonadaceae in clinic A, and with members of the genus Methylobacterium in clinic B. In general, only the isolates belonging to the more common taxonomic groups were detected in different sampling dates, eventually due to their persistence in the water lines.

Most of the bacteria detected are recognized environmental microbes, only occasionally related with disease. One of the groups heavily represented in clinic B was methylobacteria, which, in spite of the recognized environmental distribution, are of concern in health care facilities $(20 ; 25)$. Methylobacterium spp. is a known oligotroph able to stand chlorine disinfection (8). Curiously, Methylobacterium spp. have been also reported as colonizers of the oral cavity (2). Given the fact that in the current study these bacteria were also detected in the controls, the water supply is the most probable source. In clinic $\mathrm{A}$, the predominance of environmental mycobacteria and sphingomonads, at counts of $>1 \mathrm{CFU} / \mathrm{ml}$ deserves attention. Although the human health hazards associated with environmental mycobacteria are not fully understood, it is supposed they may behave as opportunistic pathogens, mainly in immunocompromised hosts (1; 13). Sphingomonads have a widespread distribution in potable water and are recognized members of biofilm structures in such habitats (4). Nevertheless, members of this group, mainly of the species Sphingomonas paucimobilis, have been described as opportunistic pathogens with nosocomial dispersion and high risk agents for immunocompromized hosts $(4 ; 7 ; 12 ; 22)$. Other organisms detected in the current study were also reported as occasional opportunistic pathogens. Examples of this are the members of the bacterial species Cupriavidus gilardii (9) or of the yeast species Cryptococcus albidus (10).

The fact that: i) some of microorganisms found were previously reported as associated to disease, ii) bacteria may reach high densities in the CFDC and iii) the use of invasive procedures in some medical dentistry practices may facilitate the infection by some microbes, mainly in immunocompromised hosts, are relevant conclusions for further risk assessment studies.

\section{ACKNOWLEDGEMENTS}

This study was financed by Fundação para a Ciência e a Tecnologia (project PTDC/AMB/70825/2006).

\section{REFERENCES}

1. Al-Mahruqi, S. H.; van Ingen J.; Al-Busaidy, S.; Boeree, M. J.; AlZadjali, S.; Patel, A.; Dekhuijzen, R.; van Soolingen, D. (2009). Clinical Relevance of Nontuberculous Mycobacteria, Oman. Emerg. Infect. 
Dis. 15, 292-294.

2. Anesti, V.; McDonald, I. R.; Ramaswamy, M.; Wade, W. G.; Kelly, D. P.; Wood, A. P. (2005). Isolation and molecular detection of methylotrophic bacteria occurring in the human mouth. Environ. Microbiol. 7, 1227-1238.

3. Barbeau, J.; Tanguay, R.; Faucher, E.; Avezard, C.; Trudel, L.; Côte, L.; Prevoste, A. P. (1996). Multiparametric analysis of waterline contamination in dental units. Appl. Environ. Microbiol. 62, 3954-3959.

4. Casadevall, A.; Freundlich, L. F.; Pirofski, L. (1992). Septic shock caused by Pseudomonas paucimobilis. Clin. Infec. Dis. 14, 784.

5. Ferreira da Silva M.; Tiago, I.; Veríssimo, A.; Boaventura, R.A.R.; Nunes, O.C.; Manaia, C.M. (2006).Antibiotic resistance of enterococci and related bacteria in an urban wastewater treatment plant. FEMS Microbiol. Ecol. 55, 322-329.

6. Franco, F. F. S.; Spratt, D.; Leao, J. C.; Porter, S. R. (2005). Biofilm formation and control in dental unit waterlines. Biofilms 2, 9-17.

7. Gomila, M.; Gascó, J.; Busquets, A.; Gil, J.; Barnabeu, R.; Buades, J. M.; Lalucat, J. (2005). Identification of culturable bacteria present in haemodialysis water and fluid. FEMS Microbiol. Ecol. 52, 101-114.

8. Hiraishi, A.; Furuhata, K.; Matsumoto, A.; Koike, K. A.; Fukuyama, M.; Tabuchi, K. (1995). Phenotypic and genetic diversity of chlorineresistant Methylobacterium strains isolated from various environments. Appl. Environ. Microbiol. 61, 2099-2107.

9. Karafin, M.; Romagnoli, M.; Fink, D. L.; Howard, T.; Rau, R.; Milstone, A. M.; Carroll, K. C. (2010). Fatal infection caused by Cupriavidus gilardii in a child with aplastic anemia. J. Clin. Microbiol. 48, 10051007.

10. Khawcharoenporn, T.; Apisarnthanarak, A.; Mundy, L. M. (2007). Nonneoformans Cryptococcal Infections, a Systematic Review. Infection 35, 51-58.

11. Kumar, S.; Atray, D.; Paiwal, D.; Balasubramanyam, G.; Duraiswamy, P.; Kulkarni, S. (2010). Dental unit waterlines: source of contamination and cross-infection. J. Hosp. Infect.; 74, 99-111.

12. Lin, J. N.; Lai, C. H.; Chen, Y. H.; Lin, H. L.; Huang, C. K.; Chen, W. F.; Wang, J. L.; Chung, H. C.; Liang, S. H.; Lin, H. H. (2010). Sphingomonas paucimobilis bacteremia in humans: 16 case reports and a literature review. J. Microbiol. Immunol. Infect. 43, 35-42.

13. Macías, A. E.; Ponce-de-León, S. (2005). Infection Control: Old Problems and New Challenges. Arch. Med. Res. 36, 637-645.
14. Mills, S. E. (2003). Waterborne pathogens and dental waterlines. Dent. Clin. North Am. 47, 545-557.

15. O'Donnell, M. J.; Shore, A. C.; Coleman, D. C. (2006). A novel automated waterline cleaning system that facilitates effective and consistent control of microbial biofilm contamination of dental chair unit waterlines: a one-year study. J. Dent. 34, 648-661.

16. O’Donnell, M. J.; Shore, A. C.; Russell, R. J.; Coleman, D. C. (2007). Optimization of the long-term efficacy of dental chair waterline disinfection by the identification and rectification of factors associated with waterline disinfection failure. J. Dent. 35, 438-51.

17. Pankhurst, C. L. (2003). Risk assessment of dental unit waterline contamination. Prim. Dent. Care 10, 5-10.

18. Pankhurst, C. L. and Coulter, W. A. (2007). Do contaminated dental unit waterlines pose a risk of infection? J. Dent. 35, 712-720.

19. Rowland, B. M. (2003). Bacterial Contamination of Dental Unit Waterlines: What is your dentist Spraying Into your Mouth? Clin. Microbiol. Newsletter 25, 73-77.

20. Sanders, J. W.; Martin, J. W.; Hooke, M.; Hooke, J. (2000). Methylobacterium mesophilicum infection: case report and literature review of an unusual opportunistic pathogen. Clin. Infect. Dis. 30, 936938.

21. Shearer, B. G. (1996). Biofilm and the dental office. J. Am. Dent. Assoc. 127,181-189.

22. Studemeiste, A. E.; Beilke, M. A.; Kirmani, N. (1987). Splenic abscess due to Clostridium difficile and Pseudomonas paucimobilis. Am. J. Gastroenterol. 82, 389-390.

23. Szymanska, J. (2007). Bacterial contamination of Water in Dental Unit Reservoirs. Ann. Agric. Environ. Med.14, 137-140.

24. Szymańska, J.; Sitkowska, J.; Dutkiewicz, J. (2008). Microbial contamination of dental unit waterlines. Ann. Agric. Environ. Med. 15, 173-179.

25. Truant, A. L.; Gulati, R.; Giger, O.; Satishchandran, V.; Caya, J. G. (1998). Methylobacterium species: an increasingly important opportunistic pathogen. Lab. Med. 29, 704-710.

26. Vaz-Moreira,I., Egas, C., Nunes, O. C., and Manaia, C. M. Culturedependent and culture-independent diversity surveys target different bacteria - a case study in a freshwater sample. Antonie van Leeuwenhoek Journal of Microbiology. 100(2):245-57.

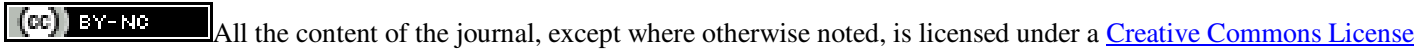

